\title{
KINERJA GURU BAHASA INDONESIA ALUMNI PROGRAM PASCASARJANA (S2) PENDIDIKAN BAHASA INDONESIA FKIP UNIVERSITAS BENGKULU
}

\author{
Suhartono \\ suhartonounib62@yahoo.com
}

\author{
Gumono \\ gumono@unib.ac.id \\ Magister (S2) Pendidikan Bahasa Indonesia, FKIP Universitas Bengkulu
}

\begin{abstract}
Abstrak
Tujuan penelitian ini adalah untuk mendapatkan deskripsi komprehensif Kinerja Guru Bahasa Indonesia Alumni Program Pascasarjana (S2) Pendidikan Bahasa Indonesia FKIP Universitas Bengkulu pada aspek kompetensi pedagogik, kompetensi profesional, kompetensi sosial, dan kompetensi kepribadian.. Penelitian ini menggunakan metode deskriptif. Populasi dalam penelitian ini adalah seluruh guru Bahasa Indonesia Alumni Program Pascasarjana (S2) Pendidikan Bahasa Indonesia FKIP Universitas Bengkulu. Sampel ditetapkan secara acak sejumlah 30 orang lulusan. Hasil penelitian memperlihatkan bahwa Kinerja Guru Bahasa Indonesia Alumni Program Pascasarjana (S2) Pendidikan Bahasa Indonesia FKIP Universitas Bengkulu berada dalam kategori sangat baik. Pada aspek kompetensi pedagogik berada dalam skala 3,16, aspek kompetensi professional berada dalam skala 3,28, aspek kompetensi sosial berada dalam skala 3,45, dan aspek kompetensi kepribadian berada dalam skala 3,46. Berdasarkan hasil penelitian ini disarankan agar guru Bahasa Indonesia Alumni Program Pascasarjana (S2) Pendidikan Bahasa Indonesia FKIP Universitas Bengkulu dapat meningkatkan kinerjanya lebih maksimal lagi.
\end{abstract}

Kata Kunci: Kinerja Guru, Alumni, Program Pascasarjana, Pend. Bahasa Indonesia UNIB

\section{PENDAHULUAN}

Istilah kinerja guru berasal dari kata job performance/actual permance (prestasi kerja atau prestasi sesungguhnya yang dicapai oleh seseorang). Jadi, menurut bahasa kinerja bisa diartikan sebagai prestasi yang nampak sebagai bentuk keberhasilan kerja pada diri seseorang. Keberhasilan kinerja juga ditentukan dengan pekerjaan serta kemampuan seseorang pada bidang tersebut. Keberhasilan kerja juga berkaitan dengan kepuasan kerja seseorang, (Mangkunegara dalam Musarofah, 2008:5).

Prestasi bukan berarti banyaknya kejuaraan yang diperoleh guru tetapi suatu keberhasilan yang salah satunya nampak dari suatu proses belajar mengajar. Untuk mencapai kinerja maksimal, guru harus berusaha mengembangkan seluruh kompetensi yang dimilikinya dan juga memanfaatkan situasi yang ada di lingkungan sekolah sesuai dengan aturan yang berlaku.

$$
\text { Menurut Davies (dalam }
$$

Musarofah, 2008:6) seseorang mempunyai empat fungsi umum yang merupakan ciri pekerjaan seorang guru yaitu: (a) Merencanakan, yaitu pekerjaan seorang guru menyusun tujuan belajar; (b) Mengorganisasikan, yaitu pekerjaan seorang guru untuk mengatur dan menghubungkan sumber- 
sumber belajar sehingga dapat mewujudkan tujuan belajar dengan cara yang paling efektif dan efesien; (c) Memimpin, yaitu pekerjaan seorang guru untuk memotivasi, mendorong, dan menstimulasikan murid-muridnya, sehingga mereka siap mewujudkan tujuan belajar; (d) Mengawasi, yaitu pekerjaan seorang guru untuk menentukan apakah fungsinya dalam mengorganisasikan dan memimpin di atas telah berhasil dalam mewujudkan tujuan yang telah dirumuskan. Jika tujuan belum dapat diwujudkan, maka guru harus menilai dan mengatur kembali situasinya dan mengubah tujuan.

\begin{tabular}{lcr}
\multicolumn{1}{c}{ Dengan } & demikian & penulis \\
menyimpulkan & bahwa kinerja & adalah \\
kemampuan & seseorang & untuk \\
melaksanakan & tugasnya & dengan
\end{tabular}
mencapai hasil yang memuaskan, guna tercapainya tujuan organisasi kelompok dalam suatu unit kerja. Jadi, kinerja guru dalam proses belajar mengajar adalah kemampuan guru dalam melaksanakan tugasnya sebagai pengajar yang memiliki keahlian mendidik dan mengajar dalam rangka pembinaan peserta didik untuk tercapainya tujuan pendidikan nasional.

Seorang guru harus memiliki kinerja yang baik terutama pada saat proses belajar berlangsung, guru diharapkan memiliki ilmu yang cukup sesuai bidangnya. Menurut Sukadi dalam Musarofah (2001:7) guru yang profesional memiliki tugas pokok yaitu merencanakan pembelajaran, melaksanakan pembelajaran, mengevaluasi pembelajaran, menindak lanjuti hasil pembelajaran, serta melakukan bimbingan dan konseling. Adapun penjelasan dari ke lima tugas pokok tersebut yaitu: (a) Merencanakan
Kegiatan

Melaksanakan

Pembelajaran;

Mengevaluasi Pembelajaran;

Menindak Lanjuti Hasil Pembelajaran; dan (e) melaksanakan bimbingan dan konseling.

Keberhasilan seorang guru bisa dilihat apabila kriteria-kriteria yang ada telah tercapai secara keseluruhan. Jika kriteria telah tercapai berarti pekerjaan seseorang dianggap telah memiliki kualitas kerja dan kemampuan yang baik. Kemampuan yang harus dimiliki guru telah disebutkan dalam Peraturan Pemerintah RI No. 19 Tahun 2005 tentang Standar Nasional Pendidikan pasal 28 ayat 3 yang berbunyi: kompetensi sebagai agen pembelajaran pada jenjang pendidikan dasar dan menengah serta pendidikan anak usia dini meliputi kompetensi pedagogik, kompetensi kepribadian, kompetensi profesional, dan kompentensi sosial.

Metode yang digunakan dalam penelitian ini adalah metode deskriptif. Metode ini sangat cocok untuk memperoleh gambaran yang jelas tentang objek yang akan dianalisis, sebagaimana yang diungkapkan Moleong (2000:6), menyatakan bahwa dala metode deskriptif data yang dikumpulkan berupa kata-kata bukan angka. Jadi, metode deskriptif adalah untuk mendapatkan gambaran yang jelas berupa fakta secara sistematis, faktual, dan cermat. Metode ini digunakan untuk mengungkapkan atau menggambarkan bagaimana Kinerja Guru Bahasa Indonesia alumni Program Pascasarjana (S2) Pendidikan Bahasa Indonesia FKIP Universitas Bengkulu. 
Populasi dalam penelitian ini adalah seluruh guru Bahasa Indonesia Alumni Program Pascasarjana (S2) Pendidikan Bahasa Indonesia FKIP Universitas Bengkulu dari tahun 20072015 yang berjumlah 412 orang.

Sampel yang digunakan dalam penelitian ini adalah sampel acak (random sampling). Jumlah sampel sebanyak 27 orang guru. Responden yang akan melakukan penilaian terhadap guru Bahasa Indonesia Alumni Program Pascasarjana (S2) Pendidikan Bahasa Indonesia FKIP Universitas Bengkulu adalah pengawas sekolah, kepala sekolah, dan siswa yaitu dengan mengisi kuesioner yang telah disediakan oleh peneliti. Pengawas sekolah, kepala sekolah, dan siswa merupakan pihak yang terlibat langsung dalam lingkungan kerja guru, sehingga mereka dianggap lebih tahu bagaimana kemampuan, kualitas, dan kinerja guru Bahasa Indonesia Alumni Program Pascasarjana
(S2) Pendidikan Bahasa Indonesia FKIP Universitas Bengkulu .

Instrumen penelitian yang digunakan untuk mengumpulkan data dalam penelitian ini berbentuk kuesioner. Dalam kuesioner ini peneliti akan mendapatkan informasi mengenai kinerja guru Bahasa Indonesia yang alumni Program Pascasarjana (S2) Pendidikan Bahasa Indonesia FKIP Universitas Bengkulu, meliputi kompetensi: pedagogik, kepribadian, professional, dan sosial

\section{HASIL DAN PEMBAHASAN}

Hasil penelitian memperlihatkan bahwa kinerja guru Bahasa Indonesia Alumni Program Pascasarjana (S2) Pendidikan Bahasa Indonesia FKIP Universitas Bengkulu pada aspek kompetensi pedagogik, profesional, sosial, dan kepribadian tergolong sangat baik, hal ini dapat dilihat pada tabel sebagai berikut:

Tabel. Rata-rata kinerja guru Bahasa Indonesia Alumni Program Pascasarjana (S2) Pendidikan Bahasa Indonesia FKIP Universitas Bengkulu

\begin{tabular}{|l|l|l|l|l|}
\hline \multirow{2}{*}{ No } & \multirow{2}{*}{ Kompetensi } & Rata-rata & \multicolumn{2}{l|}{} \\
\cline { 3 - 5 } & & Pengawas & Kepsek & Siswa \\
\hline 1 & Pedagogik & 3,20 & 3,14 & 3,16 \\
\hline 2 & Profesional & 3,14 & 3,02 & 3,38 \\
\hline 3 & Sosial & 3,57 & 3,48 & 3,30 \\
\hline 4 & Kepribadian & 3,45 & 3,54 & 3,40 \\
\hline
\end{tabular}

Berdasarkan tabel di atas, kinerja guru Bahasa Indonesia Alumni Program Pascasarjana (S2) Pendidikan Bahasa Indonesia FKIP Universitas Bengkulu pada aspek kompetensi pedagogik dari 14 pertanyaan yang disediakan untuk pengawas menunjukkan angka sangat baik dengan nilai rata-rata 3,20 .
Pendapat kepala sekolah dari 9 pertanyaan yang disediakan menunjukkan bahwa kinerja guru Bahasa Indonesia Alumni Program Pascasarjana (S2) Pendidikan Bahasa Indonesia FKIP Universitas Bengkulu aspek kompetensi pedagogik sangat baik dengan nilai ratarata 3,14. Penilaian siswa dari 11 
pertanyaan yang disediakan menunjukkan bahwa kinerja guru Bahasa Indonesia Alumni Program Pascasarjana (S2) Pendidikan Bahasa Indonesia FKIP Universitas Bengkulu aspek kompetensi pedagogik sangat baik dengan nilai ratarata 3,16. Pada aspek kompetensi pedagogik guru Bahasa Indonesia Alumni Program Pascasarjana (S2) Pendidikan Bahasa Indonesia FKIP Universitas Bengkulu telah memenuhi kriteria yang menunjang kemampuan aspek pedagogik, mulai dari persiapan mengajar yang mencakup merancang dan melaksanakan skenario pembelajaran, memilih metode pembelajaran, media pembelajaran, mengevaluasi serta melaksanakan tindak lanjut pembelajaran kepada peserta didik.

Kinerja guru Bahasa Indonesia Alumni Program Pascasarjana (S2) Pendidikan Bahasa Indonesia FKIP Universitas Bengkulu pada aspek kompetensi profesional berdasarkan data penelitian dan analisis hasil penelitian menunjukkan bahwa dari 15 pertanyaan yang disediakan untuk pengawas menunjukkan angka sangat baik dengan nilai rata-rata 3,14. Menurut pendapat kepala sekolah dari 13 pertanyaan yang disediakan menunjukkan bahwa kinerja guru Bahasa Indonesia Alumni Program Pascasarjana (S2) Pendidikan Bahasa Indonesia FKIP Universitas Bengkulu aspek kompetensi profesional baik dengan nilai rata-rata 3,02 . Pendapat siswa dari 3 pertanyaan yang disediakan menunjukkan bahwa kinerja guru Bahasa Indonesia Alumni Program Pascasarjana (S2) Pendidikan Bahasa Indonesia FKIP Universitas Bengkulu aspek kompetensi profesional sangat baik dengan nilai rata-rata 3,38.
Pada aspek kompetensi profesional ini guru Bahasa Indonesia Alumni Program Pascasarjana (S2) Pendidikan Bahasa Indonesia FKIP Universitas Bengkulu dalam menjalankan profesiannya telah memahami materi ajar yang ada dalam kurikulum sekolah, memahami struktur, konsep, dan metode keilmuan yang menaungi atau koheren dengan materi ajar, memahami hubungan konsep antar mata pelajaran terkait, dan menerapkan konsepkonsep keilmuan dalam kehidupan sehari-hari.

Aspek kompetensi sosial merupakan kemampuan guru untuk berkomunikasi dan bergaul secara efektif dengan peserta didik, sesama pendidik, tenaga kependidikan, orang tua/ wali peserta didik, dan masyarakat sekitar. Kinerja guru Bahasa Indonesia Alumni Program Pascasarjana (S2) Pendidikan Bahasa Indonesia FKIP Universitas Bengkulu pada aspek kompetensi sosial ini menunjukkan bahwa dari 4 pertanyaan yang disediakan untuk pengawas menunjukkan bahwa kinerja guru Bahasa Indonesia Alumni Program Pascasarjana (S2) Pendidikan Bahasa Indonesia FKIP Universitas Bengkulu aspek kompetensi sosial sangat baik dengan nilai rata-rata 3,57. Menurut pendapat kepala sekolah dari 4 pertanyaan yang disediakan menunjukkan bahwa kinerja guru Bahasa Indonesia Alumni Program Pascasarjana (S2) Pendidikan Bahasa Indonesia FKIP Universitas Bengkulu aspek kompetensi sosial sangat baik dengan nilai rata-rata 3,48 . Pendapat siswa dari 5 pertanyaan yang disediakan menunjukkan bahwa kinerja guru Bahasa Indonesia Alumni Program Pascasarjana (S2) Pendidikan Bahasa Indonesia FKIP Universitas Bengkulu aspek kompetensi sosial sangat 
baik dengan nilai rata-rata 3,30. Dalam aspek kompetensi sosial guru Bahasa Indonesia Alumni Program Pascasarjana (S2) Pendidikan Bahasa Indonesia FKIP Universitas Bengkulu telah menunjukkan kemampuan dirinya dalam menghadapi orang lain yaitu kemampuan berkomunikasi dan bergaul dengan siswa-siswi, sesama tenaga pengajar, wali murid dan masyarakat sekitar.

Selanjutnya berdasarkan data penelitian dan analisis hasil penelitian yang telah dilakukan dapat diketahui bahwa kinerja guru Bahasa Indonesia Alumni Program Pascasarjana (S2) Pendidikan Bahasa Indonesia FKIP Universitas Bengkulu pada aspek kompetensi kepribadian menurut pendapat pengawas dari 8 pertanyaan yang disediakan menunjukkan bahwa kinerja guru Bahasa Indonesia Alumni Program Pascasarjana (S2) Pendidikan Bahasa Indonesia FKIP Universitas Bengkulu aspek kompetensi kepribadian sangat baik dengan nilai rata-rata 3,45. Menurut pendapat kepala sekolah dari 7 pertanyaan yang disediakan menunjukkan bahwa kinerja guru Bahasa Indonesia Alumni Program Pascasarjana (S2) Pendidikan Bahasa Indonesia FKIP Universitas Bengkulu aspek kompetensi kepribadian sangat baik dengan nilai rata-rata 3,54. Menurut pendapat siswa dari 5 pertanyaan yang disediakan menunjukkan bahwa kinerja guru Bahasa Indonesia Alumni Program Pascasarjana (S2) Pendidikan Bahasa Indonesia FKIP Universitas Bengkulu aspek kompetensi kepribadian sangat baik dengan nilai rata-rata 3,40. Pada aspek kompetensi kepribadian guru Bahasa Indonesia Alumni Program Pascasarjana (S2) Pendidikan Bahasa Indonesia FKIP Universitas Bengkulu mampu menunjukkan kepribadian yang mantap, stabil, dewasa, arif, berwibawa, berahlak mulia dan menjadi teladan bagi peserta didik. Guru bertindak sesuai dengan norma yang berlaku, memberikan contoh perilaku yang baik kepada siswa, melaksanakan tugas tepat pada waktunya, mematuhi peraturan di sekolah, melaksanakan ketaatan dalam menjalankan ajaran agama, dan mampu menerima serta menanggapi saran dari dari orang lain. Untuk melihat rata-rata kinerja guru Bahasa Indonesia Alumni Program Pascasarjana (S2) Pendidikan Bahasa Indonesia FKIP Universitas Bengkulu secara keseluruhan dapat dilihat pada tabel berikut:

TabelKinerja Guru Bahasa Indonesia Alumni Program Pascasarjana (S2) Pendidikan Bahasa Indonesia FKIP Universitas Bengkulu Bengkulu

\begin{tabular}{|l|l|l|l|}
\hline No & Aspek Kompetensi & Rata-rata & Kategori \\
\hline 1 & Pedagogik & 3,16 & Sangat baik \\
\hline 2 & Profesional & 3,18 & Sangat baik \\
\hline 3 & Sosial & 3,45 & Sangat baik \\
\hline 4 & Kepribadian & 3,46 & Sangat baik \\
\hline & Rata-rata & 3,31 & Sangat baik \\
\hline
\end{tabular}


Berdasarkan tabel di atas, nilai rata-rata keseluruhan kinerja guru Bahasa Indonesia Alumni Program Pascasarjana (S2) Pendidikan Bahasa Indonesia FKIP Universitas Bengkulu dilihat pada aspek kompetensi pedagogik, profesional, sosial, dan kepribadian nilai rata-rata pada setiap aspek bila dilihat berdasarkan kategorinya termasuk kategori sangat baik, jadi dapat ditarik kesimpulan bahwa kinerja guru Bahasa Indonesia Alumni Program Pascasarjana (S2) Pendidikan Bahasa Indonesia FKIP Universitas Bengkulu berada pada kategori sangat baik dengan perolehan nilai rata-rata 3,31 . Nilai tersebut bila dilihat berdasarkan kategorinya termasuk kategori sangat baik.

Hasil penelitian dan pembahasan mengenai kinerja guru Bahasa Indonesia Alumni Program Pascasarjana (S2) Pendidikan Bahasa Indonesia FKIP Universitas Bengkulu menunjukkan angka yang sangat baik, angka sangat baik ini diperoleh dari penilaian pengawas, kepala sekolah yang semuanya bukan berasal dari bidang studi Bahasa Indonesia, penulis berpendapat bahwa pengawas dan kepala sekolah kurang mengetahui kinerja guru khususnya guru Bahasa Indonesia Alumni Program Pascasarjana (S2) Pendidikan Bahasa Indonesia FKIP Universitas Bengkulu . Pengawas sekolah yang berasal dari bidang studi lain membuat penilaian terhadap kinerja guru Bahasa Indonesia Alumni Program Pascasarjana (S2) Pendidikan Bahasa Indonesia FKIP Universitas Bengkulu menjadi tidak objektif. Pengawas tidak mengetahui apa yang harus dikuasai oleh guru Bahasa Indonesia, dia juga tidak tahu bagaimana cara mengatasi masalah yang dihadapi oleh guru, mencari solusi bersama terhadap permasalahan yang dihadapi. Untuk itu perlu lagi perhatian dari pemerintah agar dalam menunjuk seseorang dalam sebuah pekerjaan hendaknya sesuai dengan profesinya masing-masing, pengawas sekolah yang dipilih harus sesuai dengan bidang studinya, agar apa yang ingin dicapai dapat menunjukkan hasil yang sesuai dengan keadaan yang sesungguhnya.

Hasil penelitian ini bertolak belakang dengan latar belakang yang dipaparkan oleh penulis. Pada awalnya penulis berpendapat bahwa guru yang telah lulus sertifikasi tidak mampu untuk meningkatkan kinerjanya, setelah kembali ke sekolah masing-masing banyak guru yang tidak tahu bagaimana cara ia meningkatkan kinerjanya. Guru yang dicap sebagai pendidik profesional setelah lulus sertifikasi, sebagian besar dalam praktiknya malah tidak sesuai dengan yang diharapkan. Guru-guru yang sudah lulus sertifikasi umumnya tidak menunjukkan kemajuan, baik dari sisi pedagogik, kepribadian, profesional, maupun sosial. Guru hanya aktif menjelang sertifikasi, tetapi setelah dinyatakan lulus, kualitas mereka justru semakin menurun. Hasil penelitian ini juga sangat bertolak belakang dengan hasil yang portofolio serta Pendidikan dan Latihan Profesi Guru yang dilaksanakan di Universitas Bengkulu pada tahun 2008, menunjukkan bahwa kemampuan guru Bahasa Indonesia Alumni Program Pascasarjana (S2) Pendidikan Bahasa Indonesia FKIP Universitas Bengkulu masih dibawah rata-rata.

Program sertifikasi guru banyak menuai kontroversi dan disinyalir hanya sekadar formalitas tanpa diikuti kualitas kinerja guru yang meningkat. Muslich 
(2007:7) mengungkapkan bahwa kualitas guru di Indonesia masih tergolong relatif rendah. Hal ini disebabkan oleh tidak terpenuhinya kualitas pendidikan minimal. Data dari Direktorat Tenaga Kependidikan Dikdasmen Depdiknas menunjukkan terdapat $317.112(71,2 \%)$ guru SMP yang tidak memenuhi kualifikasi pendidikan minimal. Fenomena ini bisa terjadi karena pengawas sekolah, kepala sekolah, dan siswa tidak mampu untuk menilai bagaimana sebenarnya sosok guru yang alumni S2 Pendidikan Bahasa Indonesia. Padahal pengawas sekolah dan kepala sekolah harus mengetahui tolak ukur untuk menilai kinerja guru, mereka harus mampu memahami hal apa saja yang harus dikuasai dan dimiliki oleh guru serta menilai bagaimana kinerja guru, khususnya guru Bahasa Indonesia yang telah berkualifikasi pendidikan S2

\section{SIMPULAN}

Berdasarkan hasil penelitian dan pembahasan dapat ditarik kesimpulan bahwa kinerja guru Bahasa Indonesia Alumni Program Pascasarjana (S2) Pendidikan Bahasa Indonesia FKIP Universitas Bengkulu berada dalam kategori sangat baik. Hal tersebut dapat dirinci sebagai berikut:

1. Pada aspek kompetensi pedagogik, guru Bahasa Indonesia Alumni Program Pascasarjana (S2) Pendidikan Bahasa Indonesia FKIP Universitas Bengkulu telah merancang dan melaksanakan skenario pembelajaran, memilih metode, media, serta alat evaluasi yang digunakan untuk peserta didik dan pengembangan peserta didik untuk mengaktualisasikan berbagai potensi yang
2. dimilikinya.

3. Pada aspek kompetensi profesional, guru Bahasa Indonesia Alumni Program Pascasarjana (S2) Pendidikan Bahasa Indonesia FKIP Universitas Bengkulu menunjukkan penguasaan materi kurikulum mata pelajaran di sekolah dan substansi keilmuan yang menaungi materinya, serta penguasaan terhadap struktur dan metodologi keilmuan.

4. Pada aspek kompetensi sosial, guru Bahasa Indonesia Alumni Program Pascasarjana (S2) Pendidikan Bahasa Indonesia FKIP Universitas Bengkulu mampu untuk berkomunikasi dan bergaul secara efektif dengan peserta didik, sesama pendidik, tenaga kependidikan, orang tua peserta pendidikan, dan masyarakat sekitar.

5. Pada aspek kompetensi kepribadian, guru Bahasa Indonesia Alumni Program Pascasarjana (S2) Pendidikan Bahasa Indonesia FKIP Universitas Bengkulu mampu menunjukkan kepribadian yang mantap, stabil, dewasa, arif, dan berwibawa, menjadi teladan bagi peserta didik, dan berahlak mulia.

6. Dengan demikian, dapat disimpulkan kinerja guru Bahasa Indonesia Alumn Program Pascasarjana (S2) Pendidikan Bahasa Indonesia FKIP Universitas Bengkulu, berdasarkan penilaian pengawas, kepala sekolah, dan siswa tergolong sangat baik. 


\section{DAFTAR PUSTAKA}

Arikunto, Suharsimi. 2006. Prosedur Penelitian Suatu Pendekatan Praktik. Jakarta: PT Asdi Mahasatya.

Dasuki, Achmad dkk. 2010. Sertifikasi Guru dalam Jabatan Buku 1 Pedoman penetapan peserta. Jakarta: Ditjen PMPTK

Moleong, Lexy J. 2000. Metodologi Penelitian Kualitatif. Bandung : Remaja Rodas Karya.

Musarofah. 2008. Kinerja guru di MTS Al-Wathoniyah di Cilungup Duren Sawit- Jakarta Timur. Jakarta: Skripsi Fakultas IImu Tarbiyah dan Keguruan UIN Syarif Hidayatullah.

Muslich, Mansur. 2007. Sertifikasi Guru Menuju Profesionalisme Pendidik. Jakarta: PT Bumi Aksara.

Samani Muchlas dkk. 2010. Sertifikasi Guru dalam Jabatan Buku 2 Petunjuk Teknis Pelaksanaan Sertifikasi. Jakarta: Ditjen PMPTK

Samani Muchlas dkk. 2010. Sertifikasi Guru dalam Jabatan Buku 3 Pedoman penyususnan Portofolio. Jakarta: Ditjen PMPTK

Samani Muchlas dkk. 2010. Sertifikasi Guru dalam Jabatan Buku 4 Petunjuk Teknis Sertifikasi untuk Guru. Jakarta: Ditjen PMPTK
Sujianto Agus Eko. 2007. Aplikasi Statistik dengan SPSS untuk Pemula. Jakarta: Prestasi Pustaka.

Trianto dan Tutik Titik Triwulan. 2007. Sertifikasi Guru dan Upaya Peningkatan Kualifikasi, Kompetensi \& Kesejahteraan. Jakarta: Prestasi Pustaka.

Yamin, Martinis dan Maisah. 2010. Standarisasi Kinerja Guru. Jakarta: Gaung Persada Press. 